\title{
Optimal Replenishment and Payment Policies for Deteriorating Inventory Model with Price-Sensitive Trapezoidal Demand Under Biddable Two-Part Trade Credit
}

\author{
Nita H. Shah ${ }^{1, *}$, Digeshkumar B. Shah ${ }^{2}$, Dushyantkumar G. Patel ${ }^{3}$ \\ ${ }^{1}$ Department of Mathematics, Gujarat University, Ahmedabad-380009, Gujarat, India \\ ${ }^{2}$ Department of Mathematics, L. D. Engg. College, Ahmedabad- 380015, Gujarat, India \\ ${ }^{3}$ Department of Mathematics, Govt. Poly.for Girls, Ahmedabad- 380015, Gujarat, India \\ *Corresponding Author: nitahshah@gmail.com
}

Copyright (c) 2013 Horizon Research Publishing All rights reserved.

\begin{abstract}
In general, researchers analyzing inventory models under two-part trade credit considered that the buyer either pays full purchase cost during the pre-specified credit period and take the advantage of cash discount or settles the account within a longer allowable credit period at the regular purchase price. In this paper, we model decision policies when buyer may pay part of purchase cost within a permissible shorter credit period and gets a cash discount in purchase cost and then the remaining account is settled within the longer permissible credit period. The demand rate is considered to be price-sensitive trapezoidal and units in inventory are subject to constant rate of deterioration. An algorithm is proposed to compute the optimal retail price, cycle time and biddable fraction of payments to be paid which maximizes the decision maker's profit per unit time. Numerical examples are given to illustrate the proposed problem. It is observed that the buyer is beneficial under biddable two-part trade credit scenario as compared to either not paying anything within shorter credit period or paying in full within longer permissible credit period.
\end{abstract}

Keywords Inventory, Deterioration, Price-Sensitive Trapezoidal Demand, Two-Part Trade Credit Financing, Biddable Payment

\section{Introduction}

The offer of trade credit from vendor attracts a buyer to stock more goods without any investment. Zhou (2009) documented that around $70-80 \%$ of business between the players of the business is based on trade credit. In general, the vendor adopts either anet credit period in which a buyer has to settle payment in a fixed period or a two-part trade credit in which a buyer gets a discount in purchase price of an item if payment is made within an offered shorter period, otherwise the full payment is to be settled within the pre-specified longer credit period. For example, under ' $2 / 10$ net 30 ', the widely used two-part trade credit scenario, a buyer will get $2 \%$ discount in the purchase cost of an item if the account is settled within 10-days of receipts of goods otherwise settles the full purchase cost within 30-days. This type of trade credit is termed as two-part trade credit. Two-part trade credit is denoted as ' $\beta / M_{1}$ net $M_{2}$ ' under which the buyer receives a cash discount of $\beta$ percentage in unit purchase cost if payment is made by $M_{l}$; otherwise the buyer pays by $M_{2}$ at a regular purchase cost.

The buyeris prominent decision maker who bids for preferable contract terms and thereby reducinghis investments in terms of purchase cost (Klapper etal. 2012). Fabbri and Klapper (2011) advocated that when the buyer has constraint of investment, the supplier should offer flexible payment schemes to increasethe demand from the buyer resulting increase of cash in-flow. Using this concept, Zhou et al. (2012) modeled a flexible two- part trade $\operatorname{credit}\left(\beta / M_{1}\right.$ net $\left.M_{2}\right)$ under which the buyer is allowed to pay $\lambda$ percent of the total purchase cost within $M_{1}$ timeand avail of the cash discount of $\beta$ percentage in unit purchase price and then settle the remaining account of $(1-\lambda)$ percent of the total purchase cost at regular price within allowable period $M_{2}$. The demand rate was considered to be constant. However, in electronic industry, textile industry, food and beverages industry etc., the demand increases linearly with time for some time point, attains constant in some time interval and then decreases exponentially with time. This type of demand is termed as trapezoidal demand (Cheng et al. (2011)). The recent 
examples are of iphone-4S, Blackberry Bold 9790, air seats in aviation industry during vacation or week-ends, where the trapezoidal demand is observed.

The concept of trade credit was first modeled by Goyal (1985). The analysis of this promotional tool was explored by many researchers. Refer to review articles on inventory modeling and trade credit by Goyal et al. (2008) and Shah et al. (2010). Ouyang et al. (2009) determined an economic order quantity for deteriorating items with partial trade credit linked to order quantity. Huang (2003) discussed inventory model when the retailer passes some credit period to the buyer which is offered to him by the supplier. Shah and Raykundaliya (2011) determined inventory policies when demand declines under two -level trade credit schemes. Ho (2011)discussed integrated decision for two players of a supply chain under a two-level trade credit policy. Zhou et al. (2012) developed a two-echelon non-cooperative supply chain model when the retailer has floor space constraint and demand is stock-dependent under delay in payments policy. Other related articles are by Teng and Chang (2009), Min et al. (2010), Tenget al. (2012) and their cited references.

In this research, the optimal retail price, cycle time and payment policy for the buyer is worked out under a biddable two-part trade credit policy when demand is price-sensitive trapezoidal and units ininventory deteriorate at a constant rate. Using numerical data, it is established that the proposed concept is favorable to buyer as compared to the traditional one.

The rest of the paper is organized as follows: In section 2, notations and assumptions are listed. Section 3 is mathematical model of the proposed concept. In section 4, algorithm is proposed to determine the optimal policy. Section 5 exhibits numerical examples and sensitivity analysis. Section 6 concludes the study.

\section{Notations and Assumptions}

\subsection{Notations}

\section{$R \quad(=R(P, t))$ Market demand rate}

The demand $R(P, t)$ is considered to be a trapezoidal type whose functional form is

$$
R(P, t)= \begin{cases}f(t) P^{-\eta} & ; 0 \leq t \leq u_{1} \\ R_{0} P^{-\eta} & ; u_{1} \leq t \leq u_{2} \\ g(t) P^{-\eta} ; u_{2} \leq t \leq T\end{cases}
$$

where $u_{1}$ is time point when the increasing demand function $f(t)$ changes to constant demand and $u_{2}$ is the time point from where constant demand starts decreasing exponentially. In this study, we take $f(t)$ to be liner in $t$, $R_{0}=f\left(u_{1}\right)=g\left(u_{2}\right)$ and $g(t)$ to be exponentially decreasing in $t$. So the demand function is

$$
R(P, t)=\left\{\begin{array}{l}
R_{1}(P, t) ; 0 \leq t \leq u_{1} \\
R_{2}(P, t) ; u_{1} \leq t \leq u_{2} \\
R_{3}(P, t) ; u_{2} \leq t \leq T
\end{array}\right.
$$

where;

$$
\begin{aligned}
& R_{1}(P, t)=a\left(1+b_{1} t\right) P^{-\eta} \\
& R_{2}(P, t)=a\left(1+b_{1} u_{1}\right) P^{-\eta} \\
& R_{3}(P, t)=a\left(1+b_{1} u_{1}\right) e^{-b_{2}\left(t-u_{2}\right)} P^{-\eta}
\end{aligned}
$$

where; $a>0$ is scale demand, $0<b_{1}, b_{2}<1$ denote the rates of change of demand, $\eta>1$ is mark-up and $u_{1}$ and $u_{2}$ are time points at which demand pattern changes. (Fig. 1)

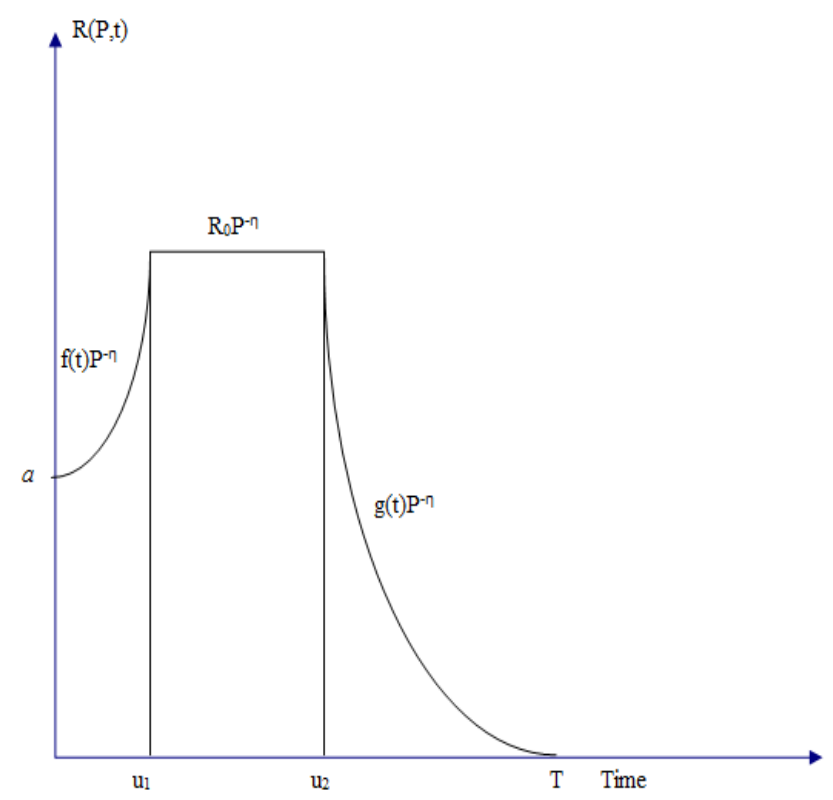

Figure 1. Price-sensitive time dependent trapezoidal demand

Hence, total demand, $R P$ during cycle time $[0, T]$ is given by

$$
R P=\int_{0}^{u_{1}} R_{1}(P, t) d t+\int_{u_{1}}^{u_{2}} R_{2}(P, t) d t+\int_{u_{2}}^{T} R_{3}(P, t) d t
$$

$\theta$ Constant deterioration rate of units; $0<\theta<1$

$A_{b} \quad$ Ordering cost per order (\$/order)

$C_{b} \quad$ Unit purchase cost (\$/unit)

$P \quad$ Unit selling price (\$/unit) (a decision variable)

$I_{b} \quad$ Holding cost charge fraction per unit per year excluding interest charges

$I_{b e} \quad$ Interest earned per dollar per year by the buyer

$I_{b c} \quad$ Interest charged per dollar in stocks per year for 
the buyer

$$
\left(\beta / M_{1} \text { net } M_{2}\right)
$$

The supplier offers a $\beta$ discount $(0<\beta<1)$ if the payment is made within $M_{1}$ time, otherwise the account against purchases made is to be settled at time $M_{2}$; where $M_{2}>M_{1} \geq 0$

$\lambda \quad$ The percentage of the purchase cost that the buyer pays to the vendor at the time $M_{1}$ (a decision variable)

$1-\lambda$ The fraction of the purchase cost that the buyer pays to the vendor at the time $M_{2}$

$T \quad$ Cycle time (a decision variable)

$\pi(\lambda, P, T) \quad$ The buyer's profit function per unit time

\subsection{Assumptions}

The development of mathematical model is based on following assumptions.

The buyer stocks single item.

Shortages are not allowed. Lead-time is zero.

The demand rate $R(P, t)$ is price-sensitive trapezoidal.

$$
R(P, t)=\left\{\begin{array}{l}
R_{1}(P, t) ; 0 \leq t \leq u_{1} \\
R_{2}(P, t) ; u_{1} \leq t \leq u_{2} \\
R_{3}(P, t) ; u_{2} \leq t \leq T
\end{array} ;\right.
$$

where

$$
\begin{aligned}
& R_{1}(P, t)=a\left(1+b_{1} t\right) P^{-\eta} \\
& R_{2}(P, t)=a\left(1+b_{1} u_{1}\right) P^{-\eta} \\
& R_{3}(P, t)=a\left(1+b_{1} u_{1}\right) e^{-b_{2}\left(t-u_{2}\right)} P^{-\eta}
\end{aligned}
$$

where $a>0$ is scale demand, $0<b_{1}, b_{2}<1$ denote the rates of change of demand, $\eta>1$ is mark-up and $u_{1}$ and $u_{2}$ are time points at which demand pattern changes.

The buyer can accumulate revenue and earn interest from the beginning of the cycle until the end of the allowable trade credit offered by the vendor. In $\left(\beta / M_{1}, M_{2}\right)$ netcredit scenario, the buyer can earn interest during $\left[0, M_{2}\right]$ at rate $I_{b e}$.

The deteriorated units can neither be replaced nor repaired during the cycle time.

\section{Mathematical Model}

The total profit per unit time of the buyer comprises of the following components.

1) Gross revenue per unit time; $G R=\frac{\left(P-C_{b}\right) Q}{T} ;(Q$ is defined in Appendix A)

2) Ordering cost per unit time; $O C_{b}=\frac{A_{b}}{T}$

3) Holding cost excluding interest charges per unit time; $H C_{b}=\frac{C_{b} I_{b}}{T} \int_{0}^{T} I(t) d t \quad$ (Appendix B)

4) Discount revenue per unit time; $D R=\frac{\beta \lambda C_{b} Q}{T}$

The interest earned and/or charged per unit time depends upon the lengths of $T, M_{1}$ and $M_{2}$. Three cases may arise: (i) $T \leq M_{1}$; (ii) $M_{1}<T \leq M_{2}$; and (iii) $T>M_{2}$. Using assumption (4), we compute the interest charged/earned per unit time for the buyer as follows:

Case 1: $\boldsymbol{T} \leq \boldsymbol{M}_{\mathbf{1}}$ (Fig. 2)

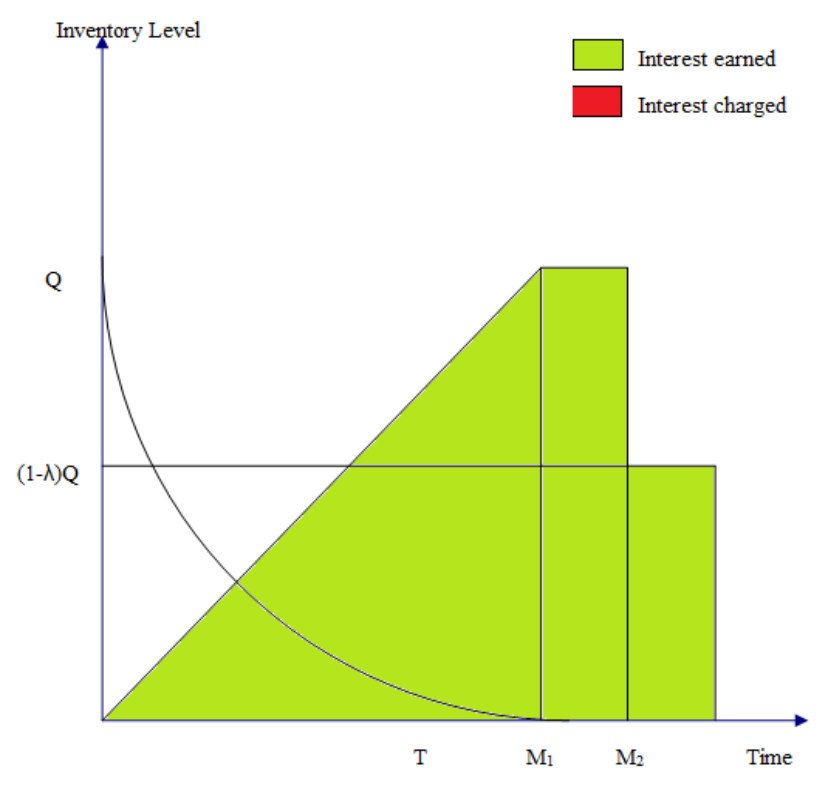

Figure 2. $T \leq M_{1}$

Here, the cycle time ends before the shorter permissible credit period. The buyer has sold all the items before the due payment time and generated revenue which facilitated to earn interest on the generated revenue during $[0, T]$, on full sales revenue during period $\left[T, M_{1}\right]$ and on $(1-\lambda)$ portion of full sales revenue during the period $\left[M_{1}, M_{2}\right]$. Hence, the total interest earned per unit time; $I E_{1}$ is 


$$
\begin{aligned}
I E_{1}= & \frac{P I_{b e}\left[\int_{0}^{u_{1}} t \cdot R_{1}(P, t) d t+\int_{u_{1}}^{u_{2}} t \cdot R_{2}(P, t) d t+\int_{u_{2}}^{T} t \cdot R_{3}(P, t) d t\right]}{T}\left[\int_{0}^{u_{1}} R_{1}(P, t) d t+\int_{u_{1}}^{u_{2}} R_{2}(P, t) d t+\int_{u_{2}}^{T} R_{3}(P, t) d t\right] \\
& +\frac{P I_{b e}\left(M_{1}-T\right]}{T}\left[\int_{0}^{u_{1}}(1-\lambda)\left(M_{2}-M_{1}(P, t) d t+\int_{u_{1}}^{u_{2}} R_{2}(P, t) d t+\int_{u_{2}}^{T} R_{3}(P, t) d t\right]\right.
\end{aligned}
$$

\section{Case 2: $M_{1}<T \leq M_{2}$}

In this scenario, the buyer does $\lambda \%$ of payment against total purchase cost at discounted purchase price $M_{1}$ which is before the completion of the cycle time. Depending on values of $M_{1}$ and $\lambda T$, the possible two sub-cases are (i) $\lambda T<M_{1}$ and (ii) $\lambda T \geq M_{1}$.

In our model, the demand rate is changing at two time points viz. $u_{1}$ and $u_{2}$. Let us compute interest earned per unit time for $\lambda T<M_{1}$ by considering lengths of $u_{1}$ and $u_{2}$.

Sub case2.1: $\lambda \boldsymbol{T}<\boldsymbol{M}_{\mathbf{1}}$ (Fig. 3)

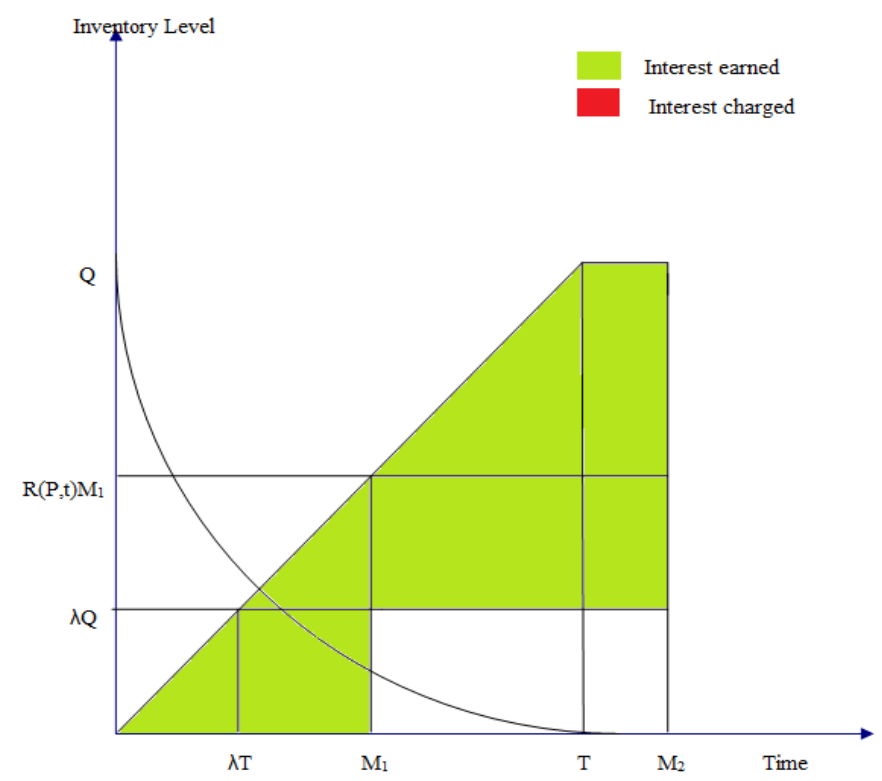

Figure 3. $\lambda T<M_{1}<T \leq M_{2}$

In this case, the buyer has generated more revenue than the $\lambda$ fraction of purchase cost at time $M_{1}$. Also $T \leq M_{2}$, the buyer has sold off all the units before the payment is due. Hence, the interest charged $I C_{2.1}\left(\lambda T<M_{1}\right)$ for the buyer is zero. As shown in figure 3, the buyer accumulate interest (1) during $\left[0, M_{1}\right]$, the buyer earns interest on sales revenue; (2) at time $M_{1}$, the retailer pay $\lambda$ portion of purchase cost to the vendor and earns interest on $(1-\lambda)$ portion of purchase cost during $\left[M_{1}, M_{2}\right]$; and (3) after time $M_{1}$, the buyer earns interest on sales revenue by selling the item until $T$ - time units, and on $(1-\lambda)$ fraction of full sales revenue during $\left[T, M_{2}\right]$. Hence, the total interest is 


$$
\begin{aligned}
I E_{2.1}( & \left.\lambda T<M_{1}\right)=\frac{P I_{b e}}{T} \int_{0}^{M_{1}} t \cdot R(P, t) d t+\frac{P I_{b e}\left(M_{2}-M_{1}\right)(1-\lambda)}{T} \int_{0}^{T} R(P, t) d t-\frac{P I_{b e}}{T}\left[\int_{M_{1}}^{T} t \cdot R(P, t) d t\right] \\
= & \left\{\begin{array}{l}
I E_{2.1}\left(u_{1}<u_{2}<\lambda T<M_{1}\right) \\
I E_{2.1}\left(\lambda T<u_{1}<u_{2}<M_{1}\right) \\
I E_{2.1}\left(\lambda T<M_{1}<u_{1}<u_{2}\right) \\
I E_{2.1}\left(u_{1}<\lambda T<u_{2}<M_{1}\right) \\
I E_{2.1}\left(u_{1}<\lambda T<M_{1}<u_{2}\right) \\
I E_{2.1}\left(\lambda T<u_{1}<M_{1}<u_{2}\right)
\end{array}\right.
\end{aligned}
$$

Sub case 2.2: $\lambda T \geq M_{1}$ (Fig. 4)

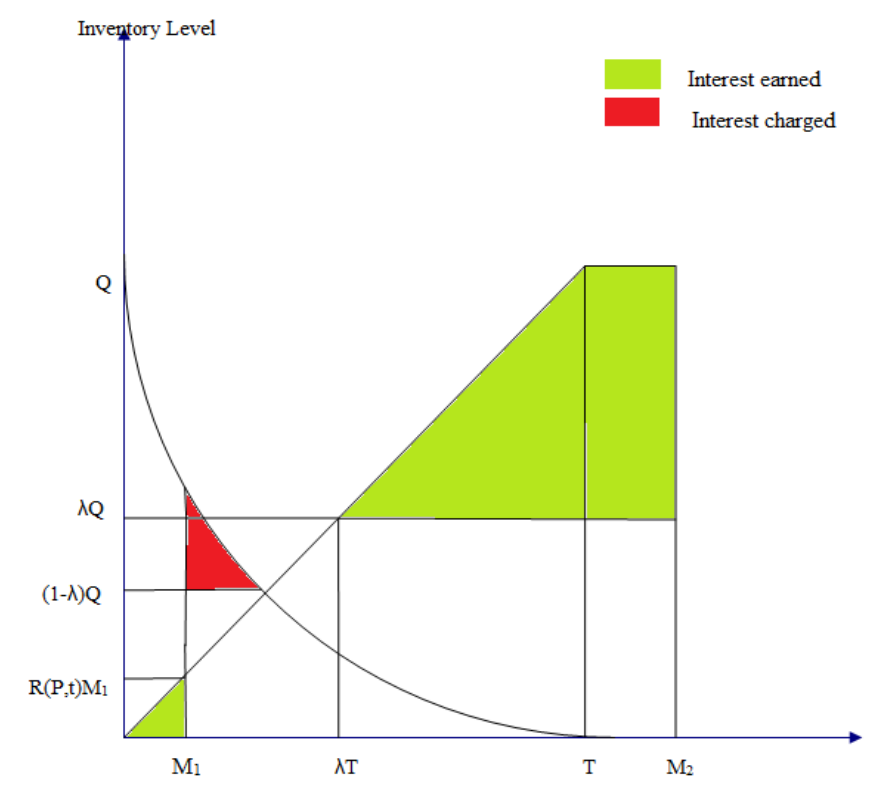

Figure 4. $\lambda T \geq M_{1}$

In this scenario, to avail of the discount in unit purchase price, the buyer pays $\lambda$ percentage of purchase $\operatorname{cost}$ by time $M_{1}$. The buyer's sales revenue is less than the $\lambda$ percentage of purchase cost because the offered credit period $M_{1}$ is less than the time $\lambda T$. Hence, the buyer pays interest charges for the items in the stock during $\left[M_{1}, \lambda T\right]$ at an interest rate $I_{b c}$ per dollar per year. Therefore, the interest charged per unit time is given by

$$
\begin{aligned}
I C_{2.2}\left(\lambda T \geq M_{1}\right)= & \frac{C_{b}(1-\beta) I_{b c}}{T} \int_{M_{1}}^{\lambda T} I(t) d t \\
= & \left\{\begin{array}{l}
I C_{2.2}\left(u_{1}<u_{2}<M_{1} \leq \lambda T\right) \\
I C_{2.2}\left(M_{1}<u_{1}<u_{2} \leq \lambda T\right) \\
I C_{2.2}\left(M_{1} \leq \lambda T<u_{1}<u_{2}\right) \\
I C_{2.2}\left(u_{1}<M_{1}<u_{2} \leq \lambda T\right) \\
I C_{2.2}\left(u_{1}<M_{1} \leq \lambda T<u_{2}\right) \\
I C_{2.2}\left(M_{1}<u_{1} \leq \lambda T<u_{2}\right)
\end{array}\right.
\end{aligned}
$$

The buyer earns interest (1) during $\left[0, M_{1}\right]$ on the generated sales revenue; (2) during $[\lambda T, T]$, on the sales revenue by 
selling the items and on $(1-\lambda)$ fraction of full sales revenue during the period $\left[T, M_{2}\right]$. Hence, the total interest earned per unit time is

$$
\begin{aligned}
I E_{2.2}\left(\lambda T \geq M_{1}\right)=\frac{P I_{b e}}{T} \int_{0}^{M_{1}} t \cdot R(P, t) d t+\frac{P I_{b e}(1-\lambda)}{T} \int_{\lambda T}^{T} t \cdot R(P, t) d t+\frac{P(1-\lambda) I_{b e}}{T} \int_{0}^{T} R(P, t) d t\left(M_{2}-T\right) \\
=\left\{\begin{array}{l}
I E_{2.2}\left(u_{1}<u_{2}<M_{1} \leq \lambda T\right) \\
I E_{2.2}\left(M_{1}<u_{1}<u_{2} \leq \lambda T\right) \\
I E_{2.2}\left(M_{1} \leq \lambda T<u_{1}<u_{2}\right) \\
I E_{2.2}\left(u_{1}<M_{1}<u_{2} \leq \lambda T\right) \\
I E_{2.2}\left(u_{1}<M_{1} \leq \lambda T<u_{2}\right) \\
I E_{2.2}\left(M_{1}<u_{1} \leq \lambda T<u_{2}\right)
\end{array} \quad \text { (See Appendix } F\right)
\end{aligned}
$$

Case 3: $T>M_{2}$

Depending on values of $M_{1}, M_{2}$ and $\lambda T$, the possible two sub-cases are (i) $\lambda T<M_{1}$ (ii) $M_{1} \leq \lambda T<M_{2}$ and (iii) $\lambda T \geq M_{2}$. The values of $u_{1}$ and $u_{2}$ will sub branch each sub-cases as discussed below.

Sub-case 3.1: $\lambda \boldsymbol{T}<\boldsymbol{M}_{1}$ (Fig.5)

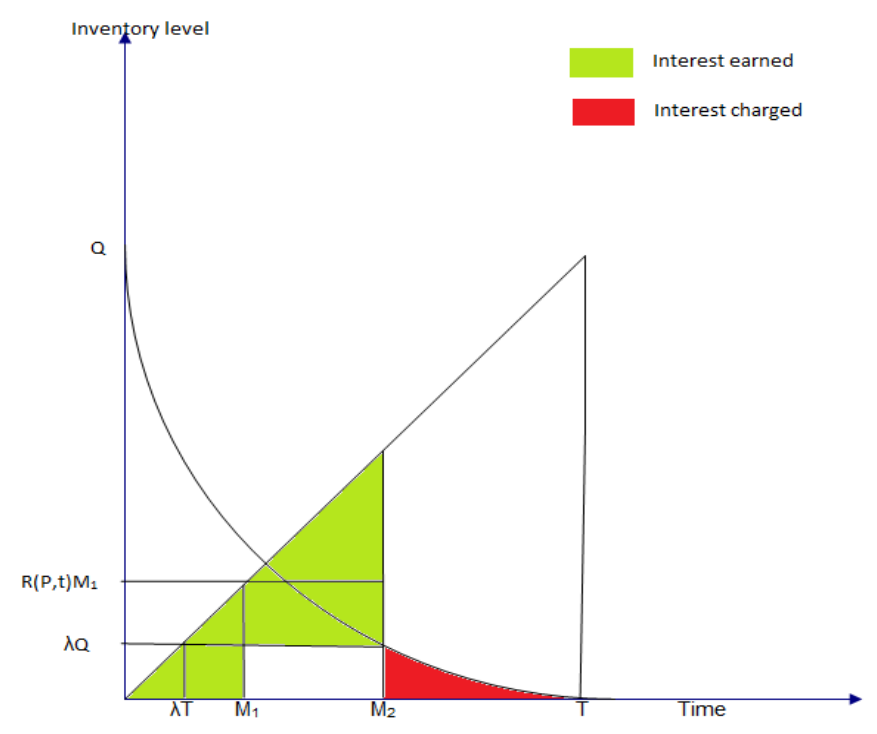

Figure 5. $\lambda T<M_{1}<M_{2}<T$

Here, the buyer has sufficient amount in the account to pay $\lambda$ fraction of purchase cost at time $M_{1}$. As $M_{2}<T$, the buyer has unsold stock in the inventory at $M_{2}$. So the interest charges per unit time is

$$
\begin{aligned}
I C_{3.1}\left(\lambda T<M_{1}\right)= & \frac{C_{b} I_{b c}}{T} \int_{M_{2}}^{T} I(t) d t \\
& =\left\{\begin{array}{l}
I C_{3.1}\left(u_{1}<u_{2}<M_{1}<M_{2}\right) \\
I C_{3.1}\left(M_{1}<u_{1}<u_{2}<M_{2}\right) \\
I C_{3.1}\left(M_{1}<M_{2}<u_{1}<u_{2}\right) \\
I C_{3.1}\left(u_{1}<M_{1}<u_{2}<M_{2}\right) \\
I C_{3.1}\left(u_{1}<M_{1}<M_{2}<u_{2}\right) \\
I C_{3.1}\left(M_{1}<u_{1}<M_{2}<u_{2}\right)
\end{array} \quad \text { (See Appendix } G\right)
\end{aligned}
$$


The buyer earns interest on (1) the generated revenue during $\left[0, M_{1}\right]$ (2) at time $M_{1}$, the buyer pays $\lambda$ percentage of the purchase cost and earns interest on $(1-\lambda)$ fraction of purchase cost during $\left[M_{1}, M_{2}\right]$ and (3) on the average sales revenue during $\left[T, M_{2}\right]$. Hence, the total interest earned per unit time is

$$
\begin{aligned}
I E_{3.1}\left(\lambda T<M_{1}\right)=\frac{P I_{b e}}{T} \int_{0}^{\lambda T} t \cdot R(P, t) d t+\frac{P I_{b e}}{T} \int_{\lambda T}^{M_{1}} t \cdot R(P, t) d t\left(M_{2}-M_{1}\right)+\frac{P I_{b e}}{T} \int_{M_{1}}^{M_{2}} t \cdot R(P, t) d t \\
=\left\{\begin{array}{l}
I E_{3.1}\left(u_{1}<u_{2}<M_{1}<M_{2}\right) \\
I E_{3.1}\left(M_{1}<u_{1}<u_{2}<M_{2}\right) \\
I E_{3.1}\left(M_{1}<M_{2}<u_{1}<u_{2}\right) \\
I E_{3.1}\left(u_{1}<M_{1}<u_{2}<M_{2}\right) \\
I E_{3.1}\left(u_{1}<M_{1}<M_{2}<u_{2}\right) \\
I E_{3.1}\left(M_{1}<u_{1}<M_{2}<u_{2}\right)
\end{array} \quad \text { See Appendix } H\right)
\end{aligned}
$$

Sub-case 3.2: $\boldsymbol{M}_{1} \leq \lambda \boldsymbol{T}<\boldsymbol{M}_{2}$ (Fig.6)

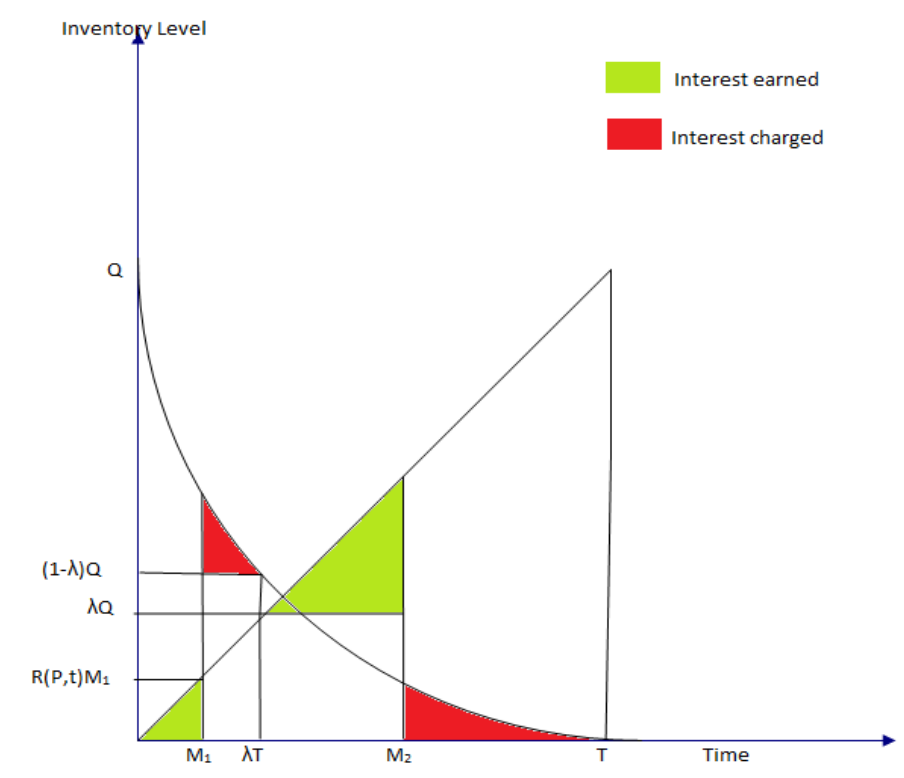

Figure 6. $M_{1} \leq \lambda T<M_{2}$

Here, at time $M_{1}$, the buyer pays $\lambda$ fraction of purchase cost and take advantage of discount in unit purchase price. Since $M_{1} \leq \lambda T$, the buyer pays interest charges during $\left[M_{1}, \lambda T\right]$ and also during $\left[M_{2}, T\right]$. Hence, total interest paid per unit time by the buyer is 


$$
\begin{aligned}
I C_{3.2}\left(M_{1} \leq \lambda T<M_{2}\right)= & \frac{C_{b}(1-\beta) I_{b c}}{T} \int_{M_{1}}^{\lambda T} I(t) d t+\frac{C_{b} I_{b c}}{T} \int_{M_{2}}^{T} I(t) d t \\
= & \left\{\begin{array}{l}
I C_{3.2}\left(u_{1}<u_{2}<M_{1} \leq \lambda T<M_{2}\right) \\
I C_{3.2}\left(M_{1}<u_{1}<u_{2} \leq \lambda T<M_{2}\right) \\
I C_{3.2}\left(M_{1} \leq \lambda T<u_{1}<u_{2}<M_{2}\right) \\
I C_{3.2}\left(M_{1} \leq \lambda T<M_{2}<u_{1}<u_{2}\right) \\
I C_{3.2}\left(u_{1}<M_{1}<u_{2} \leq \lambda T<M_{2}\right) \\
I C_{3.2}\left(u_{1}<M_{1} \leq \lambda T<u_{2}<M_{2}\right) \\
I C_{3.2}\left(u_{1}<M_{1} \leq \lambda T<M_{2}<u_{2}\right) \\
I C_{3.2}\left(M_{1}<u_{1} \leq \lambda T<u_{2}<M_{2}\right) \\
I C_{3.2}\left(M_{1}<u_{1} \leq \lambda T<M_{2}<u_{2}\right) \\
I C_{3.2}\left(M_{1} \leq \lambda T<u_{1}<M_{2}<u_{2}\right)
\end{array}\right.
\end{aligned}
$$

The interest earned by the buyer per unit time is

$$
\begin{aligned}
I E_{3.2}\left(M_{1} \leq \lambda T<M_{2}\right)= & \frac{P I_{b e}}{T} \int_{0}^{M_{1}} t \cdot R(P, t) d t+\frac{P I_{b e}}{T} \int_{\lambda T}^{M_{2}} t \cdot R(P, t) d t \\
& =\left\{\begin{array}{l}
I E_{3.2}\left(u_{1}<u_{2}<M_{1} \leq \lambda T<M_{2}\right) \\
I E_{3.2}\left(M_{1}<u_{1}<u_{2} \leq \lambda T<M_{2}\right) \\
I E_{3.2}\left(M_{1} \leq \lambda T<u_{1}<u_{2}<M_{2}\right) \\
I E_{3.2}\left(M_{1} \leq \lambda T<M_{2}<u_{1}<u_{2}\right) \\
I E_{3.2}\left(u_{1}<M_{1}<u_{2} \leq \lambda T<M_{2}\right) \\
I E_{3.2}\left(u_{1}<M_{1} \leq \lambda T<u_{2}<M_{2}\right) \\
I E_{3.2}\left(u_{1}<M_{1} \leq \lambda T<M_{2}<u_{2}\right) \\
I E_{3.2}\left(M_{1}<u_{1} \leq \lambda T<u_{2}<M_{2}\right) \\
I E_{3.2}\left(M_{1}<u_{1} \leq \lambda T<M_{2}<u_{2}\right) \\
I E_{3.2}\left(M_{1} \leq \lambda T<u_{1}<M_{2}<u_{2}\right)
\end{array}\right.
\end{aligned}
$$

Sub-case 3.3: $\boldsymbol{M}_{2} \leq \lambda \boldsymbol{T}$ (Fig. 7)

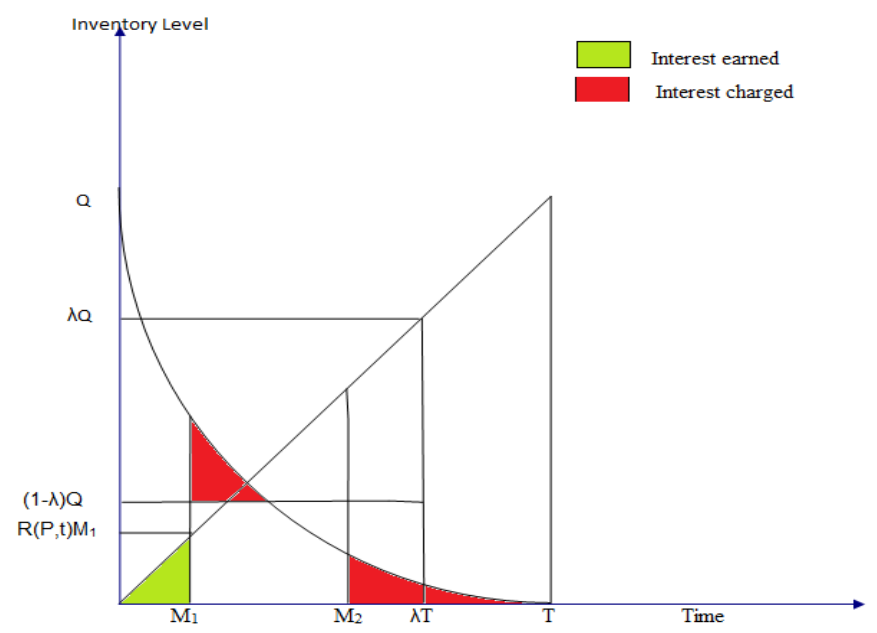

Figure 7. $M_{2} \leq \lambda T$ 
In this scenario, the interest earned per unit time by the buyer is given by

$$
\begin{aligned}
I E_{3.3}\left(M_{2} \leq \lambda T\right)= & \frac{P I_{b e}}{T} \int_{0}^{M_{1}} t \cdot R(P, t) d t \\
& =\left\{\begin{array}{l}
I E_{3.3}\left(u_{1}<u_{2}<M_{1}<M_{2} \leq \lambda T\right) \\
I E_{3.3}\left(M_{1}<u_{1}<u_{2}<M_{2} \leq \lambda T\right) \\
I E_{3.3}\left(M_{1}<M_{2}<u_{1}<u_{2} \leq \lambda T\right) \\
I E_{3.3}\left(M_{1}<M_{2} \leq \lambda T<u_{1}<u_{2}\right) \\
I E_{3.3}\left(u_{1}<M_{1}<u_{2}<M_{2} \leq \lambda T\right) \\
I E_{3.3}\left(u_{1}<M_{1}<M_{2}<u_{2} \leq \lambda T\right) \\
I E_{3.3}\left(u_{1}<M_{1}<M_{2} \leq \lambda T<u_{2}\right) \\
I E_{3.3}\left(M_{1}<u_{1}<M_{2}<u_{2} \leq \lambda T\right) \\
I E_{3.3}\left(M_{1}<u_{1}<M_{2} \leq \lambda T<u_{2}\right) \\
I E_{3.3}\left(M_{1}<M_{2}<u_{1} \leq \lambda T<u_{2}\right)
\end{array}\right.
\end{aligned}
$$

(See Appendix K)

and the interest paid per unit time on the unsold items by the buyer is

$$
\begin{aligned}
I C_{3.3}\left(M_{2} \leq \lambda T\right)= & \frac{C_{b}(1-\beta) I_{b c}}{T} \int_{M_{1}}^{\lambda T} I(t) d t+\frac{C_{b}(1-\lambda) I_{b c}}{T} \int_{M_{2}}^{\lambda T} I(t) d t+\frac{C_{b}(1-\lambda) I_{b c}}{T} \int_{\lambda T}^{T} I(t) d t \\
& =\left\{\begin{array}{l}
I C_{3.3}\left(u_{1}<u_{2}<M_{1}<M_{2} \leq \lambda T\right) \\
I C_{3.3}\left(M_{1}<u_{1}<u_{2}<M_{2} \leq \lambda T\right) \\
I C_{3.3}\left(M_{1}<M_{2}<u_{1}<u_{2} \leq \lambda T\right) \\
I C_{3.3}\left(M_{1}<M_{2} \leq \lambda T<u_{1}<u_{2}\right) \\
I C_{3.3}\left(u_{1}<M_{1}<u_{2}<M_{2} \leq \lambda T\right) \\
I C_{3.3}\left(u_{1}<M_{1}<M_{2}<u_{2} \leq \lambda T\right) \\
I C_{3.3}\left(u_{1}<M_{1}<M_{2} \leq \lambda T<u_{2}\right) \\
I C_{3.3}\left(M_{1}<u_{1}<M_{2}<u_{2} \leq \lambda T\right) \\
I C_{3.3}\left(M_{1}<u_{1}<M_{2} \leq \lambda T<u_{2}\right) \\
I C_{3.3}\left(M_{1}<M_{2}<u_{1} \leq \lambda T<u_{2}\right)
\end{array} \quad \text { (See Appendix L) }\right)
\end{aligned}
$$

The total profit per unit time of the buyer is given by

$$
\pi(\lambda, P, T)= \begin{cases}\pi_{1}(\lambda, P, T) & , T \leq M_{1} \\ \begin{cases}\pi_{2.1}(\lambda, P, T) \\ \pi_{2.2}(\lambda, P, T)\end{cases} & , M_{1}<T \leq M_{2} \\ \begin{cases}\pi_{3.1}(\lambda, P, T) \\ \pi_{3.2}(\lambda, P, T) \\ \pi_{3.3}(\lambda, P, T)\end{cases} & , M_{2} \leq T\end{cases}
$$

where

$$
\begin{gathered}
\pi_{1}(\lambda, P, T)=G R-O C_{b}-H C_{b}+D R+I E_{1} \\
\pi_{2.1}(\lambda, P, T)=G R-O C_{b}-H C_{b}+D R+I E_{2.1}-I C_{2.1}
\end{gathered}
$$

$$
\begin{gathered}
\pi_{2.2}(\lambda, P, T)=G R-O C_{b}-H C_{b}+D R+I E_{2.2}-I C_{2.2} \\
\pi_{3.1}(\lambda, P, T)=G R-O C_{b}-H C_{b}+D R+I E_{3.1}-I C_{3.1} \\
\pi_{3.2}(\lambda, P, T)=G R-O C_{b}-H C_{b}+D R+I E_{3.2}-I C_{3.2} \\
\pi_{3.3}(\lambda, P, T)=G R-O C_{b}-H C_{b}+D R+I E_{3.3}-I C_{3.3}
\end{gathered}
$$

Clearly, the objective function given in equation (1) is continuous in $\lambda, P$ and $T$. Ourgoal is to compute three decision variables that maximize buyer's annual profit $\pi(\lambda, P, T)$ per unit time for biddable payment under two-part trade credit policy.

\section{Computational Algorithm}

We outline following steps to determine optimal policies for the buyer to maximize the total profit per unit time. 
Step 1: Assign values to the inventory parameters.

Step 2: Solve $\frac{\partial \pi}{\partial \lambda}=0, \frac{\partial \pi}{\partial P}=0$ and $\frac{\partial \pi}{\partial T}=0$ simultaneously. Check conditions given in case $i ; i=1,2,3$.Identify the time scenario and find out maximum profit.

Step 3: Knowing optimal policy $(\lambda, P, T)$, compute $Q$ (given in Appendix A).

\section{Numerical Examples and Sensitivity Analysis}

Example 1: Suppose $a=3000000$ units, $\eta=1.25, b_{1}=$ $7 \%, b_{2}=5 \%, u_{1}=15$ days, $u_{2}=25$ days, $C_{b}=\$ 10 /$ unit, $A_{b}=\$ 300 /$ order, $I_{b}=10 \% /$ annum, $I_{b c}=20 \%$ /annum, $I_{b c}$ $=15 \% /$ year and $\theta=0.1$. A credit term considered is ' $4 / 10$ net 30 '. That means if buyer pays by $M_{1}=10$ days, the discount $\beta=4 \%$ in purchase cost is offered. Otherwise, payment is to be settled by $M_{2}=30$ days. Following steps outlined in section 5, the buyer's optimal fraction of payment $\lambda$ is $67 \%$ at $M_{1}$. This suggests $33 \%$ of the purchase cost should be paid at $M_{2}$. With this payment policy, the retailer's cycle time is $T=24$ days and selling price $P=$ $\$ 48.77 /$ unit. This obtains maximum profit of $\$ 9,07,737$.

The concavity of the profit with respect to retail price, cycle time is shown in fig. 9 and fig. 10 respectively. From fig. 8 , it is observed that the buyer's profit is convex with respect to biddable payment to be made at earlier date to avail of discount in unit purchase price. The 3-D plots given in figures 11-13 suggest that buyer's profit is maximum for the proposed concept.

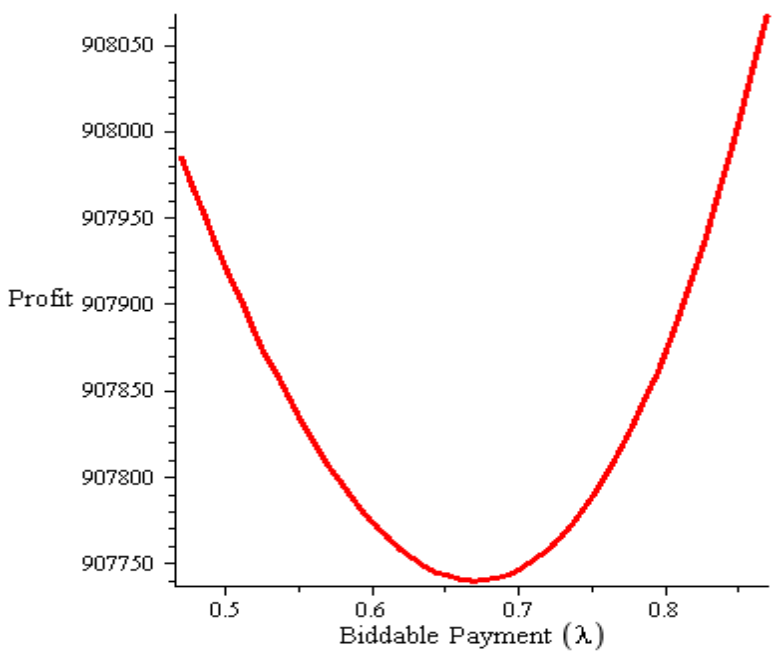

Figure 8. Convexity of profit w.r.t. biddable payment

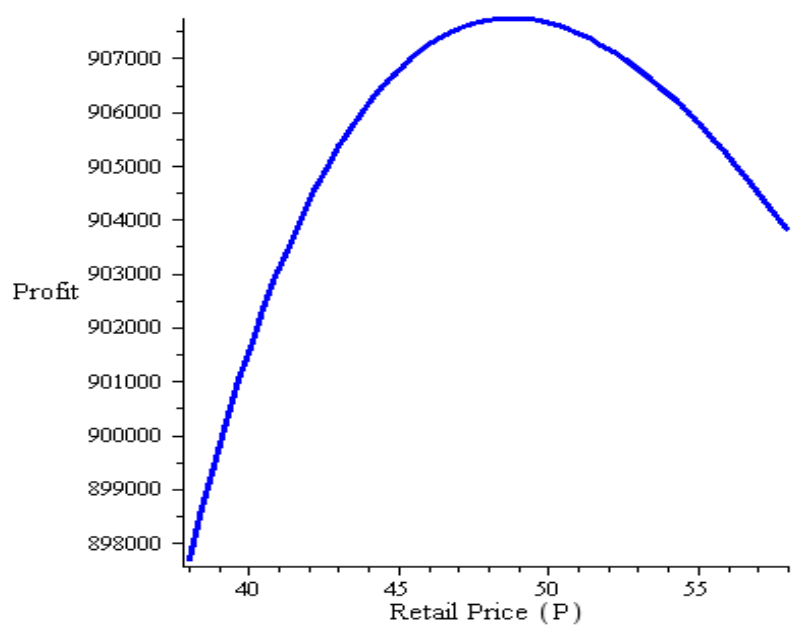

Figure 9. Concavity of profit w.r.t. retail price

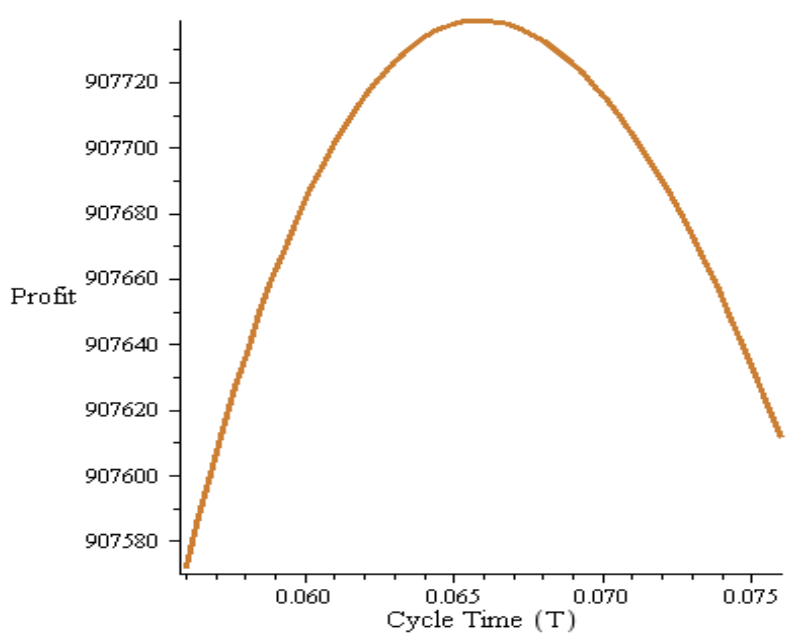

Figure 10. Concavity of profit w.r.t. cycle time

Example 2: Assuming all parametric values of the model as given in example 1 except $u_{1}=15$ days and $u_{2}=45$ days gives that $\lambda=1$ suggesting that the buyer should settle full account at $M_{1}$. The corresponding cycle time is 53 days an selling price is 48.65 . This results the maximum profit of $\$ 8$, 97,652 .

Next, we carry out the sensitivity analysis by changing inventory parameters given in example 1 as $-20 \%,-10 \%,+10 \%$ and $+20 \%$ to get managerial insights for the decision maker. In Fig. 14, variations in early payment fraction $\lambda$ are studied. It is observed that $\lambda$ has highly positive impact due to changes in scale demand and interest paid by the buyer. Though scale demand is uncontrollable, interest to be paid on unsold stock can be reduced by selling items in time $\lambda$ is positively sensitive to offered payment time and inventory carrying charge fraction. The ordering cost and the time point when demand starts decreasing exponentially are negatively related to $\lambda$. This suggests retailer to save in ordering cost by larger order though the inventory carrying charged fraction will hinder for larger order. So, the retailer should find out the trade-off 
between these two parameters. The purchase cost of an item has negative impact on $\lambda$ which suggests that the decision maker should do smaller fraction of payment at earlier date for costlier items. From Fig. 15, we see that increase in purchase cost increases selling price while other inventory parameters decrease selling price. In Fig. 16, variations in cycle time are depicted. The price elasticity, larger offered delay period and the time point when demand starts decreasing increases cycle time significantly. Increase in discount rate of units in purchase price decreases cycle time. This establishes that the offer of early payment by taking advantage of discount in unit purchase price is beneficial to the retailer. In Fig. 17, profit variations are studied. The profit sharply increases with increase in discount in unit purchase price, scale demand, early payment time, the rate at which demand increases and the time in which demand increases and remains constant. Thus, the retailer is beneficial if the inventory policies are planned considering positive impact of these parameters.

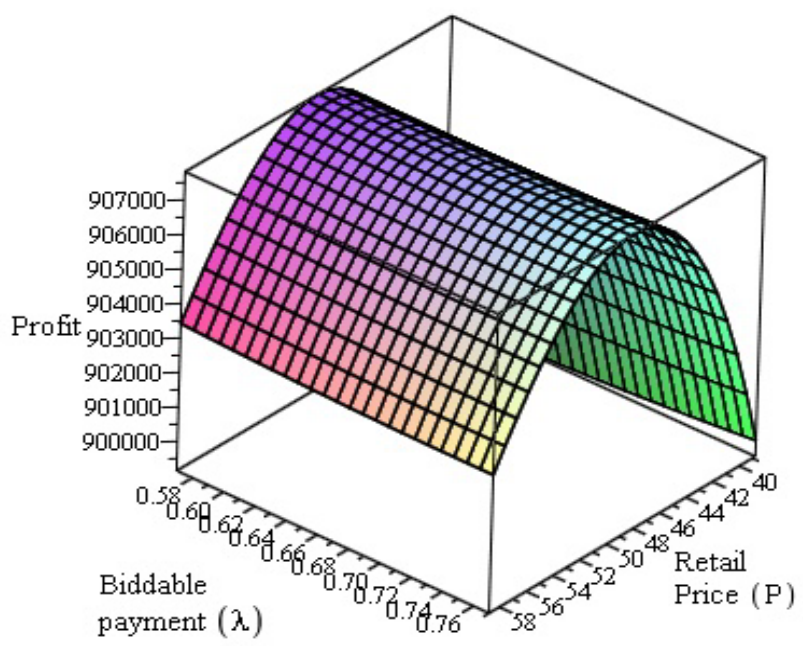

Figure 11. Concavity of profit w.r.t. biddable payment and retail price

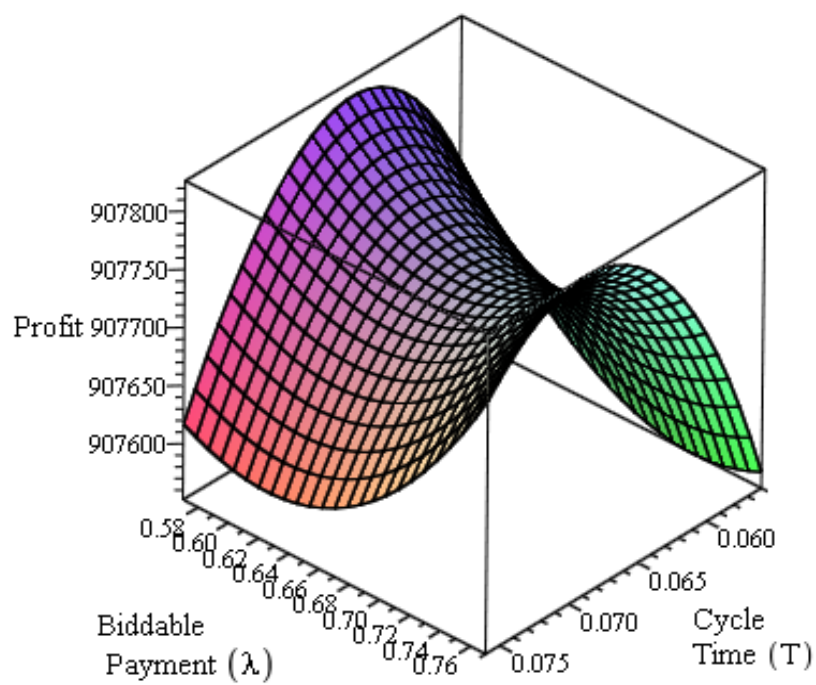

Figure 12. Concavity of profit w.r.t. biddable payment and cycle time

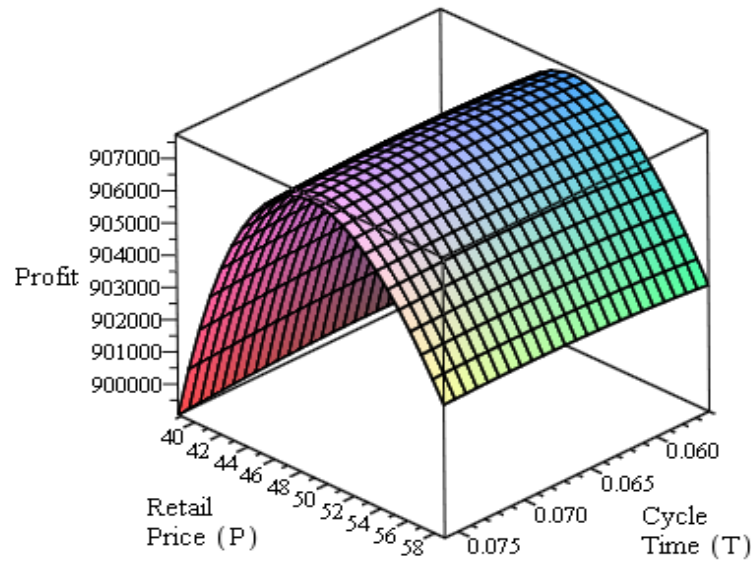

Figure 13. Concavity of profit w.r.t. retail price and cycle time

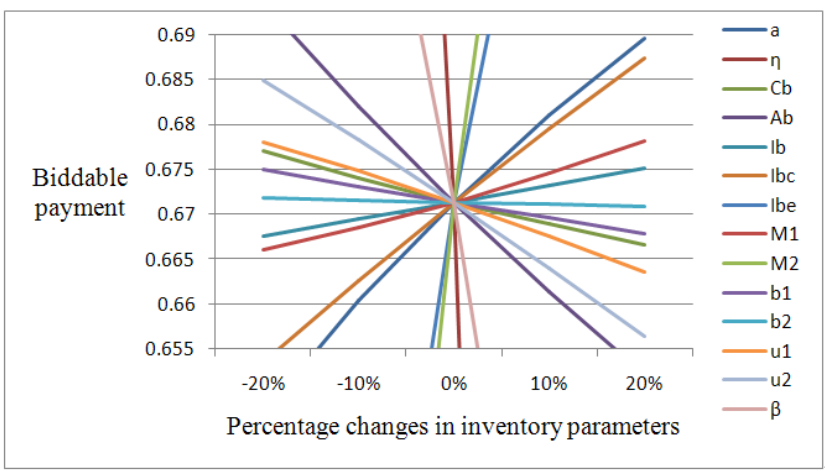

Figure 14. Sensitivity analysis of inventory parameters on biddable payment

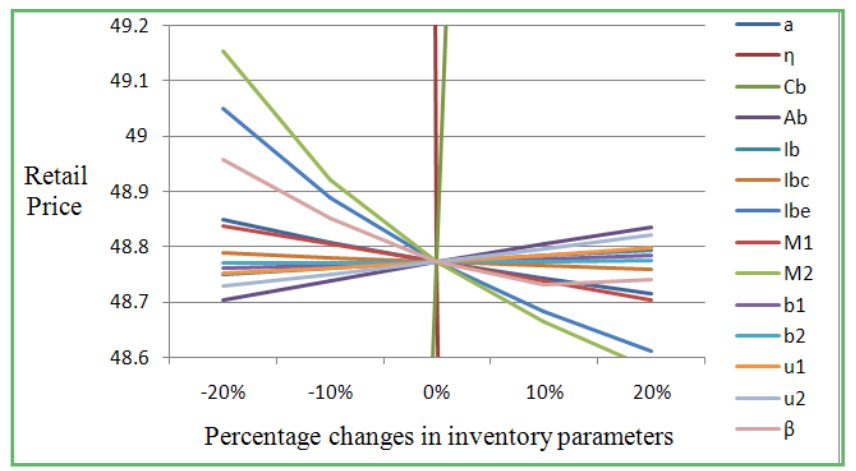

Figure 15. Sensitivity analysis of inventory parameters on retail price

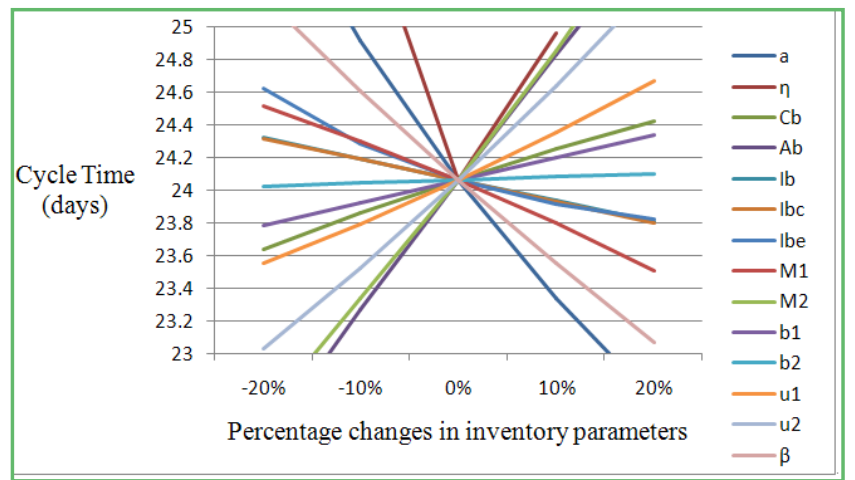

Figure 16. Sensitivity analysis of inventory parameters on cycle time 


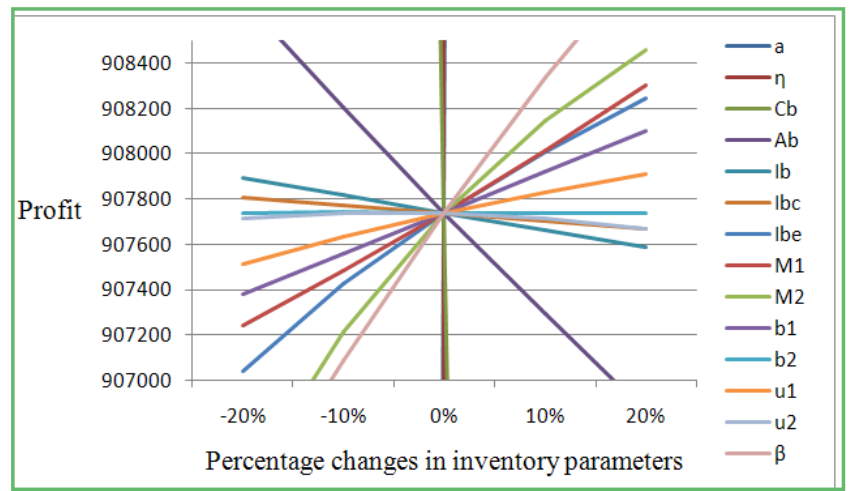

Figure 17. Sensitivity analysis of inventory parameters on profit

\section{Conclusions}

This paper analyzes the retailer's pricing, ordering and payment policies under a two-part trade credit scenario $\left(\beta / M_{1}\right.$ net $\left.M_{2}\right)$ offered by a supplier when demand rate is price-sensitive trapezoidal. In this paper, it is assumed that the supplier permits the retailer to pay any fraction of the purchase cost within time $M_{1}$ and the remaining account is to be settled by $M_{2}$; where $M_{1}<M_{2}$. The retailer's profit is maximized with respect to optimal selling price, ordering policy and payment option. Numerical examples are given to validate the proposed problem.

The given analysis will help the supplier to allow the retailer to pay fraction of purchase cost at $M_{1}$ and rest within $M_{2}$.It suggests that retailer should take advantage of time phase in which demand increases. By encouraging buyer to pay early with offer of discount in purchase price will reduce cash-out flow risk for the vendor. One can incorporate deterioration of items, finite replenishment, stochastic demand pattern etc. to get more beneficial analysis.

\section{Appendix A: Computation of Inventory at Any Instant of Time $t$ and Purchase Quantity $Q$}

The inventory level in warehouse changes due to price-sensitive trapezoidal demand and deterioration rate of units in the warehouse. The rate of change of inventory at any instant of time $t$ is governed by the differential equation

$$
\frac{d I(t)}{d t}=-R(P, t)-\theta I(t) ; 0 \leq t \leq T
$$

with the initial condition $I(T)=0$.

The solution of the differential equation is

$$
I(t)=\left\{\begin{array}{l}
I_{1}(t) ; 0 \leq t \leq u_{1} \\
I_{2}(t) ; u_{1} \leq t \leq u_{2} \\
I_{3}(t) ; u_{2} \leq t \leq T
\end{array}\right.
$$

where

$$
\begin{gathered}
I_{2}(t)=\left\{\begin{array}{l}
\frac{a P^{-\eta}\left(1+b_{1} u_{1}\right)}{\theta}\left[-1+e^{\theta u_{2}-\theta t}\right]+ \\
P^{-\eta}\left[\frac{a\left(1+b_{1} u_{1}\right) e^{b_{2} u_{2}}}{\theta-b_{2}}\right]\left[e^{-b_{2} T+\theta T-\theta t}-e^{-b_{2} u_{2}+\theta u_{2}-\theta t}\right] \\
I_{3}(t)=P^{-\eta}\left[\frac{a\left(1+b_{1} u_{1}\right) e^{b_{2} u_{2}}}{\theta-b_{2}}\right]\left[e^{-b_{2} T+\theta T-\theta t}-e^{-b_{2} t}\right]
\end{array}\right.
\end{gathered}
$$

Using $I(0)=Q$, we get 


$$
Q=\left\{\begin{array}{l}
a P^{-\eta}\left[-\frac{1}{\theta}+\frac{b_{1}}{\theta^{2}}+\frac{1+b_{1} u_{1}}{\theta} e^{\theta u_{1}}-\frac{b_{1}}{\theta^{2}} e^{\theta u_{1}}\right]+ \\
P^{-\eta} \frac{a\left(1+b_{1} u_{1}\right)}{\theta}\left[e^{\theta u_{2}}-e^{\theta u_{1}}\right]+ \\
P^{-\eta}\left[\frac{a\left(1+b_{1} u_{1}\right) e^{b_{2} u_{2}}}{\theta-b_{2}}\right]\left[e^{-b_{2} T+\theta T}-e^{-b_{2} u_{2}+\theta u_{2}}\right]
\end{array}\right.
$$

\section{Appendix B: Computation of Total Inventory during $[0, T]$}

Total inventory during $[0, T]$ is given by

$$
\int_{0}^{T} I(t) d t=\int_{0}^{u_{1}} I_{1}(t) d t+\int_{u_{1}}^{u_{2}} I_{2}(t) d t+\int_{u_{2}}^{T} I_{3}(t) d t
$$

\section{Appendix C: Computation of $I E_{2.1}\left(\lambda T<M_{1}\right)$}

$$
\begin{gathered}
I E_{2.1}\left(u_{1}<u_{2}<\lambda T<M_{1}\right)=\frac{P I_{b e}}{T}\left[\int_{0}^{u_{1}} t \cdot R_{1}(P, t) d t+\int_{u_{1}}^{u_{2}} t \cdot R_{2}(P, t) d t+\int_{u_{2}}^{M_{1}} t \cdot R_{3}(P, t) d t\right] \\
\quad+\frac{P I_{b e}(1-\lambda) R P\left(M_{2}-M_{1}\right)}{T}-\frac{P I_{b e}}{T} \int_{0}^{T-M_{1}} t \cdot R_{3}(P, t) d t \\
I E_{2.1}\left(\lambda T<u_{1}<u_{2}<M_{1}\right)=I E_{2.1}\left(u_{1}<u_{2}<\lambda T<M_{1}\right) \\
I E_{2.1}\left(\lambda T<M_{1}<u_{1}<u_{2}\right)=\frac{P I_{b e} \int_{0}^{M_{1}} t \cdot R_{1}(P, t) d t+\frac{P I_{b e} R P\left(M_{2}-M_{1}\right)}{T}}{\quad-\frac{P I_{b e}}{T}\left[\int_{M_{1}}^{u_{1}} t \cdot R_{1}(P, t) d t+\int_{u_{1}}^{u_{2}} t \cdot R_{2}(P, t) d t+\int_{u_{2}}^{T} t \cdot R_{3}(P, t) d t\right]} \\
I E_{2.1}\left(u_{1}<\lambda T<u_{2}<M_{1}\right)=I E_{2.1}\left(u_{1}<u_{2}<\lambda T<M_{1}\right) \\
I E_{2.1}\left(u_{1}<\lambda T<M_{1}<u_{2}\right)=\frac{P I_{b e}}{T}\left[\int_{0}^{u_{1}} t \cdot R_{1}(P, t) d t+\int_{u_{1}}^{M_{1}} t \cdot R_{2}(P, t) d t\right] \\
+\frac{P I_{b e}(1-\lambda) R P\left(M_{2}-M_{1}\right)}{T}-\frac{P I_{b e}}{T}\left[\int_{M_{1}}^{u_{2}} t \cdot R_{2}(P, t) d t+\int_{u_{2}}^{T} t \cdot R_{3}(P, t) d t\right] \\
I E_{2.1}\left(\lambda T<u_{1}<M_{1}<u_{2}\right)=I E_{2.1}\left(u_{1}<\lambda T<M_{1}<u_{2}\right)
\end{gathered}
$$

\section{Appendix D: Computation of $I C_{2.2}\left(\lambda T \geq M_{1}\right)$}

$$
I C_{2.2}\left(u_{1}<u_{2}<M_{1} \leq \lambda T\right)=\frac{C_{b}(1-\beta) I_{b c}}{T} \int_{M_{1}}^{\lambda T} I_{3}(t) d t
$$




$$
\begin{gathered}
I C_{2.2}\left(M_{1}<u_{1}<u_{2} \leq \lambda T\right)=\frac{C_{b}(1-\beta) I_{b c}}{T}\left[\int_{M_{1}}^{u_{1}} I_{1}(t) d t+\int_{u_{1}}^{u_{2}} I_{2}(t) d t+\int_{u_{2}}^{\lambda T} I_{3}(t) d t\right] \\
I C_{2.2}\left(M_{1} \leq \lambda T<u_{1}<u_{2}\right)=\frac{C_{b}(1-\beta) I_{b c}}{T} \int_{M_{1}}^{\lambda T} I_{1}(t) d t \\
I C_{2.2}\left(u_{1}<M_{1}<u_{2} \leq \lambda T\right)=\frac{C_{b}(1-\beta) I_{b c}}{T}\left[\int_{M_{1}}^{u_{2}} I_{2}(t) d t+\int_{u_{2}}^{\lambda T} I_{3}(t) d t\right] \\
I C_{2.2}\left(u_{1}<M_{1} \leq \lambda T<u_{2}\right)=\frac{C_{b}(1-\beta) I_{b c}}{T} \int_{M_{1}}^{\lambda T} I_{2}(t) d t \\
I C_{2.2}\left(M_{1}<u_{1} \leq \lambda T<u_{2}\right)=\frac{C_{b}(1-\beta) I_{b c}}{T}\left[\int_{M_{1}}^{u_{1}} I_{1}(t) d t+\int_{u_{1}}^{\lambda T} I_{2}(t) d t\right]
\end{gathered}
$$

\section{Appendix E: Computation of $I E_{2.2}\left(\lambda T \geq M_{1}\right)$}

$$
\begin{aligned}
I E_{2.2}\left(u_{1}<u_{2}<M_{1} \leq \lambda T\right)= & \frac{P I_{b e}}{T}\left[\int_{0}^{u_{1}} t \cdot R_{1}(P, t) d t+\int_{u_{1}}^{u_{2}} t \cdot R_{2}(P, t) d t+\int_{u_{2}}^{M_{1}} t \cdot R_{3}(P, t) d t\right] \\
& +\frac{P I_{b e}(1-\lambda)}{T} \int_{\lambda T}^{T} t \cdot R_{3}(P, t) d t+\frac{P I_{b e}(1-\lambda) R P\left(M_{2}-T\right)}{T} \\
I E_{2.2}\left(M_{1}<u_{1}<u_{2} \leq \lambda T\right)= & \frac{P I_{b e} \int_{0}^{M_{1}} t \cdot R_{1}(P, t) d t+\frac{P I_{b e}(1-\lambda)}{T} \int_{\lambda T}^{T} t \cdot R_{3}(P, t) d t}{T} \\
I E_{2.2}\left(u_{1}<M_{1}<u_{2} \leq \lambda T\right)= & \frac{P I_{b e}}{T}\left[\int_{0}^{u_{1}} t \cdot R_{1}(P, t) d t+\int_{u_{1}}^{M_{1}} t \cdot R_{2}(P, t) d t\right]+\frac{P I_{b e}(1-\lambda)}{T} \int_{\lambda T}^{T} t \cdot R_{3}(P, t) d t \\
+ & \frac{P I_{b e}(1-\lambda)\left(M_{2}-T\right)}{T}\left[\int_{0}^{u_{1}} R_{1}(P, t) d t+\int_{u_{1}}^{u_{2}} R_{2}(P, t) d t+\int_{u_{2}}^{T} R_{3}(P, t) d t\right] \\
I E_{2.2}\left(u_{1}<M_{1} \leq \lambda T<u_{2}\right)= & \frac{P I_{b e}\left[\int_{0}^{u_{1}} t \cdot R_{1}(P, t) d t+\int_{u_{1}}^{M_{1}} t \cdot R_{2}(P, t) d t\right]+\frac{P I_{b e}(1-\lambda) R P\left(M_{2}-T\right)}{T}}{T} \\
& +\frac{P I_{b e}(1-\lambda)}{T}\left[\int_{\lambda T}^{u_{2}} t \cdot R_{2}(P, t) d t+\int_{u_{2}}^{T} t \cdot R_{3}(P, t) d t\right]
\end{aligned}
$$




$$
\begin{aligned}
I E_{2.2}\left(M_{1}<u_{1} \leq \lambda T<u_{2}\right)= & \frac{P I_{b e}}{T} \int_{0}^{M_{1}} t \cdot R_{1}(P, t) d t+\frac{P I_{b e}(1-\lambda) R P\left(M_{2}-T\right)}{T} \\
& +\frac{P I_{b e}(1-\lambda)}{T}\left[\int_{\lambda T}^{u_{2}} t \cdot R_{2}(P, t) d t+\int_{u_{2}}^{T} t \cdot R_{3}(P, t) d t\right]
\end{aligned}
$$

\section{Appendix F: Computation of $I C_{3.1}\left(\lambda T<M_{1}\right)$}

$$
\begin{gathered}
I C_{3.1}\left(u_{1}<u_{2}<M_{1}<M_{2}\right)=\frac{C_{b} I_{b c}}{T} \int_{M_{2}}^{T} I_{3}(t) d t \\
I C_{3.1}\left(M_{1}<u_{1}<u_{2}<M_{2}\right)=I C_{3.1}\left(u_{1}<u_{2}<M_{1}<M_{2}\right) \\
I C_{3.1}\left(M_{1}<M_{2}<u_{1}<u_{2}\right)=\frac{C_{b} I_{b c}}{T}\left[\int_{M_{2}}^{u_{1}} I_{1}(t) d t+\int_{u_{1}}^{u_{2}} I_{2}(t) d t+\int_{u_{2}}^{T} I_{3}(t) d t\right] \\
\left.I C_{3.1}\left(u_{1}<M_{1}<u_{2}<M_{2}\right)=I C_{3.1}\left(u_{1}<u_{2}<M_{1}<M_{2}\right)\right] \\
I C_{3.1}\left(u_{1}<M_{1}<M_{2}<u_{2}\right)=\frac{C_{b} I_{b c}}{T}\left[\int_{M_{2}}^{u_{2}} I_{2}(t) d t+\int_{u_{2}}^{T} I_{3}(t) d t\right] \\
I C_{3.1}\left(M_{1}<u_{1}<M_{2}<u_{2}\right)=I C_{3.1}\left(u_{1}<M_{1}<M_{2}<u_{2}\right)
\end{gathered}
$$

\section{Appendix G: Computation of $I E_{3.1}\left(\lambda T<M_{1}\right)$}

$$
\begin{aligned}
I E_{3.1}\left(u_{1}<u_{2}<M_{1}<M_{2}\right)= & \frac{P I_{b e}}{T}\left[\int_{0}^{u_{1}} t \cdot R_{1}(P, t) d t+\int_{u_{1}}^{u_{2}} t \cdot R_{2}(P, t) d t+\int_{u_{2}}^{M_{1}} t \cdot R_{3}(P, t) d t\right] \\
& +\frac{P I_{b e}}{T} \int_{M_{1}}^{M_{2}} t \cdot R_{3}(P, t) d t+\frac{P I_{b e}\left(M_{1}-\lambda T\right)}{T} \int_{M_{1}}^{M_{2}} R_{3}(P, t) d t \\
I E_{3.1}\left(M_{1}<u_{1}<u_{2}<M_{2}\right)= & \frac{P I_{b e}}{T} \int_{0}^{M_{1}} t \cdot R_{1}(P, t) d t \\
& +\frac{P I_{b e}}{T}\left[\int_{M_{1}}^{u_{1}} t \cdot R_{1}(P, t) d t+\int_{u_{1}}^{u_{2}} t \cdot R_{2}(P, t) d t+\int_{u_{2}}^{M_{2}} t \cdot R_{3}(P, t) d t\right] \\
+ & \frac{P I_{b e}\left(M_{1}-\lambda T\right)}{T}\left[\int_{M_{1}}^{u_{1}} R_{1}(P, t) d t+\int_{u_{1}}^{u_{2}} R_{2}(P, t) d t+\int_{u_{2}}^{M_{2}} R_{3}(P, t) d t\right] \\
I E_{3.1}\left(M_{1}<M_{2}<u_{1}<\right. & \left.u_{2}\right)=\frac{P I_{b e} \int_{0}^{M_{1}} t \cdot R_{1}(P, t) d t+\frac{P I_{b e}\left(M_{1}-\lambda T\right)^{M_{2}}}{T} \int_{M_{1}} R_{1}(P, t) d t}{T} \\
& +\frac{P I_{b e}\left(M_{1}-\lambda T\right)}{T \int_{M_{1}}^{M_{2}} R_{1}(P, t) d t}
\end{aligned}
$$




$$
\begin{aligned}
I E_{3.1}\left(u_{1}<M_{1}<u_{2}<M_{2}\right)= & \frac{P I_{b e}}{T}\left[\int_{0}^{u_{1}} t \cdot R_{1}(P, t) d t+\int_{u_{1}}^{M_{1}} t \cdot R_{2}(P, t) d t\right] \\
& +\frac{P I_{b e}}{T}\left[\int_{M_{1}}^{u_{2}} t \cdot R_{2}(P, t) d t+\int_{u_{2}}^{M_{2}} t \cdot R_{3}(P, t) d t\right] \\
& +\frac{P I_{b e}\left(M_{1}-\lambda T\right)}{T}\left[\int_{M_{1}}^{u_{2}} R_{2}(P, t) d t+\int_{u_{2}}^{M_{2}} R_{3}(P, t) d t\right] \\
I E_{3.1}\left(u_{1}<M_{1}<M_{2}<u_{2}\right)= & \frac{P I_{b e}}{T}\left[\int_{0}^{u_{1}} t \cdot R_{1}(P, t) d t+\int_{u_{1}}^{M_{1}} t \cdot R_{2}(P, t) d t\right]+\frac{P I_{b e}}{T} \int_{M_{1}}^{M_{2}} t \cdot R_{2}(P, t) d t \\
+ & \frac{P I_{b e}\left(M_{1}-\lambda T\right)}{T} \int_{M_{1}}^{M_{2}} R_{2}(P, t) d t \\
I E_{3.1}\left(M_{1}<u_{1}<M_{2}<u_{2}\right)= & \frac{P I_{b e} \int_{0}^{M_{1}} t \cdot R_{1}(P, t) d t+\frac{P I_{b e}}{T}\left[\int_{M_{1}}^{u_{1}} t \cdot R_{1}(P, t) d t+\int_{u_{1}}^{M_{2}} t \cdot R_{2}(P, t) d t\right]}{T} \\
+ & \frac{P I_{b e}\left(M_{1}-\lambda T\right)}{T}\left[\int_{M_{1}}^{u_{1}} R_{1}(P, t) d t+\int_{u_{1}}^{M_{2}} R_{2}(P, t) d t\right]
\end{aligned}
$$

\section{Appendix H: Computation of $I C_{3.2}\left(M_{1} \leq \lambda T<M_{2}\right)$}

$$
\begin{gathered}
I C_{3.2}\left(u_{1}<u_{2}<M_{1} \leq \lambda T<M_{2}\right)=\frac{C_{b}(1-\beta) I_{b c}}{T} \int_{M_{1}}^{\lambda T} I_{3}(t) d t+\frac{C_{b} I_{b c}}{T} \int_{M_{2}}^{T} I_{3}(t) d t \\
I C_{3.2}\left(M_{1}<u_{1}<u_{2} \leq \lambda T<M_{2}\right)=I C_{3.1}\left(M_{1}<u_{1}<u_{2}<M_{2}\right) \\
+\frac{C_{b}(1-\beta) I_{b c}}{T}\left[\int_{M_{1}}^{u_{1}} I_{1}(t) d t+\int_{u_{1}}^{u_{2}} I_{2}(t) d t+\int_{u_{2}}^{\lambda T} I_{3}(t) d t\right] \\
I C_{3.2}\left(M_{1} \leq \lambda T<u_{1}<u_{2}<M_{2}\right)=I C_{3.1}\left(M_{1}<M_{2}<u_{1}<u_{2}\right)+\frac{C_{b}(1-\beta) I_{b c}}{T} \int_{M_{1}}^{\lambda T} I_{1}(t) d t \\
I C_{3.2}\left(M_{1} \leq \lambda T<M_{2}<u_{1}<u_{2}\right)=I C_{3.1}\left(u_{1}<M_{1}<u_{2}<M_{2}\right)+\frac{C_{b}(1-\beta) I_{b c}}{T} \int_{M_{1}}^{\lambda T} I_{1}(t) d t \\
I C_{3.2}\left(M_{1} \leq \lambda T<M_{2}<u_{1}<u_{2}\right)=I C_{3.1}\left(u_{1}<M_{1}<u_{2}<M_{2}\right)+\frac{C_{b}(1-\beta) I_{b c}}{T} \int_{M_{1}}^{\lambda T} I_{1}(t) d t \\
I C_{3.2}\left(u_{1}<M_{1}<u_{2} \leq \lambda T<M_{2}\right)=I C_{3.1}\left(u_{1}<M_{1}<M_{2}<u_{2}\right) \\
+\frac{C_{b}(1-\beta) I_{b c}}{T}\left[\int_{M_{1}}^{u_{2}} I_{2}(t) d t+\int_{u_{2}}^{\lambda T} I_{3}(t) d t\right]
\end{gathered}
$$




$$
\begin{gathered}
I C_{3.2}\left(u_{1}<M_{1} \leq \lambda T<u_{2}<M_{2}\right)=I C_{3.1}\left(u_{1}<M_{1}<u_{2}<M_{2}\right)+\frac{C_{b}(1-\beta) I_{b c}}{T} \int_{M_{1}}^{\lambda T} I_{2}(t) d t \\
I C_{3.2}\left(u_{1}<M_{1} \leq \lambda T<M_{2}<u_{2}\right)=\frac{C_{b} I_{b c}}{T} \int_{M_{2}}^{u_{2}} I_{2}(t) d t+\frac{C_{b}(1-\beta) I_{b c}}{T} \int_{M_{1}}^{\lambda T} I_{2}(t) d t \\
I C_{3.2}\left(M_{1}<u_{1} \leq \lambda T<u_{2}<M_{2}\right)=I C_{3.1}\left(M_{1}<u_{1}<u_{2}<M_{2}\right) \\
+\frac{C_{b}(1-\beta) I_{b c}}{T}\left[\int_{M_{1}}^{u_{1}} I_{1}(t) d t+\int_{u_{1}}^{\lambda T} I_{2}(t) d t\right] \\
I C_{3.2}\left(M_{1}<u_{1}<\lambda T<M_{2}<u_{2}\right)=\frac{C_{b} I_{b c}}{T}\left[\int_{M_{2}}^{u_{2}} I_{2}(t) d t+\int_{u_{2}}^{T} I_{3}(t) d t\right]+\frac{C_{b}(1-\beta) I_{b c}}{T}\left[\int_{M_{1}}^{u_{1}} I_{1}(t) d t+\int_{u_{1}}^{\lambda T} I_{2}(t) d t\right] \\
I C_{3.2}\left(M_{1} \leq \lambda T<u_{1}<M_{2}<u_{2}\right)=\frac{C_{b} I_{b c}}{T}\left[\int_{M_{2}}^{u_{2}} I_{2}(t) d t+\int_{u_{2}}^{T} I_{3}(t) d t\right]+\frac{C_{b}(1-\beta) I_{b c}}{T} \int_{M_{1}}^{\lambda T} I_{1}(t) d t
\end{gathered}
$$

\section{Appendix I: Computation of $I E_{3.2}\left(M_{1} \leq \lambda T<M_{2}\right)$}

$$
\begin{aligned}
I E_{3.2}\left(u_{1}<u_{2}<M_{1} \leq \lambda T<M_{2}\right)= & \frac{P I_{b e}}{T}\left[\int_{0}^{u_{1}} t \cdot R_{1}(P, t) d t+\int_{u_{1}}^{u_{2}} t \cdot R_{2}(P, t) d t+\int_{u_{2}}^{M_{1}} t \cdot R_{3}(P, t) d t\right] \\
& +\frac{P I_{b e}}{T} \int_{\lambda T}^{M_{2}} t \cdot R_{3}(P, t) d t \\
I E_{3.2}\left(M_{1}<u_{1}<u_{2} \leq \lambda T<\right. & \left.M_{2}\right)=\frac{P I_{b e}}{T}\left[\int_{0}^{M_{1}} t \cdot R_{1}(P, t) d t+\int_{\lambda T}^{M_{2}} t \cdot R_{3}(P, t) d t\right] \\
I E_{3.2}\left(M_{1} \leq \lambda T<u_{1}<u_{2}<M_{2}\right)= & \frac{P I_{b e}}{T}\left[\int_{0}^{M_{1}} t \cdot R_{1}(P, t) d t\right] \\
& +\frac{P I_{b e}}{T}\left[\int_{\lambda T}^{u_{1}} t \cdot R_{1}(P, t) d t+\int_{u_{1}}^{u_{2}} t \cdot R_{2}(P, t) d t+\int_{u_{2}}^{M_{2}} t \cdot R_{3}(P, t) d t\right] \\
I E_{3.2}\left(u_{1}<M_{1}<u_{2} \leq \lambda T<M_{2}\right)= & \frac{P I_{b e}}{T}\left[\int_{0}^{u_{1}} t \cdot R_{1}(P, t) d t+\int_{u_{1}}^{M_{1}} t \cdot R_{2}(P, t) d t+\int_{\lambda T}^{M_{2}} t \cdot R_{3}(P, t) d t\right] \\
M_{1} \leq \lambda T<M_{2}<u_{1}< & \left.u_{2}\right)=\frac{P I_{b e}}{T}\left[\int_{0}^{M_{1}} t \cdot R_{1}(P, t) d t+\int_{\lambda T}^{M_{2}} t \cdot R_{1}(P, t) d t\right]
\end{aligned}
$$




$$
\begin{aligned}
& I E_{3.2}\left(u_{1}<M_{1} \leq \lambda T<u_{2}<M_{2}\right)= \frac{P I_{b e}}{T}\left[\int_{0}^{u_{1}} t \cdot R_{1}(P, t) d t+\int_{u_{1}}^{M_{1}} t \cdot R_{2}(P, t) d t\right] \\
&+\frac{P I_{b e}}{T}\left[\int_{\lambda T}^{u_{2}} t \cdot R_{2}(P, t) d t+\int_{u_{2}}^{M_{2}} t \cdot R_{3}(P, t) d t\right] \\
& I E_{3.2}\left(u_{1}<M_{1} \leq \lambda T<M_{2}<u_{2}\right)= \frac{P I_{b e}}{T}\left[\int_{0}^{u_{1}} t \cdot R_{1}(P, t) d t+\int_{u_{1}}^{M_{1}} t \cdot R_{2}(P, t) d t\right] \\
&+\frac{P I_{b e}}{T}\left[\int_{\lambda T}^{M_{2}} t \cdot R_{2}(P, t) d t\right] \\
& I E_{3.2}\left(M_{1}<u_{1} \leq \lambda T<u_{2}<M_{2}\right)= \frac{P I_{b e}}{T}\left[\int_{0}^{M_{1}} t \cdot R_{1}(P, t) d t\right] \\
&+\frac{P I_{b e}}{T}\left[\int_{\lambda T}^{u_{2}} t \cdot R_{2}(P, t) d t+\int_{u_{2}}^{M_{2}} t \cdot R_{3}(P, t) d t\right] \\
&+\frac{P I_{b e}}{T}\left[\int_{\lambda T}^{u_{1}} t \cdot R_{1}(P, t) d t+\int_{u_{1}}^{u_{2}} t \cdot R_{2}(P, t) d t\right] \\
& I E_{3.2}\left(M_{1}<u_{1} \leq \lambda T<M_{2}<u_{2}\right)= \frac{P I_{b e}}{T}\left[\int_{0}^{M_{1}} t \cdot R_{1}(P, t) d t+\int_{\lambda T}^{M_{2}} t \cdot R_{2}(P, t) d t\right] \\
&\left.\frac{P I_{b e}\left[\int_{1}^{M_{1}} t \cdot R_{1}(P, t) d t\right]}{T}\right] \\
&\left.M_{0}<u_{2}<u_{2}\right)=
\end{aligned}
$$

\section{Appendix J: Computation of $I E_{3.3}\left(M_{2} \leq \lambda T\right)$}

$$
\begin{gathered}
I E_{3.3}\left(u_{1}<u_{2}<M_{1}<M_{2} \leq \lambda T\right)=\frac{P I_{b e}}{T}\left[\int_{0}^{u_{1}} t \cdot R_{1}(P, t) d t+\int_{u_{1}}^{u_{2}} t \cdot R_{2}(P, t) d t+\int_{u_{2}}^{M_{1}} t \cdot R_{3}(P, t) d t\right] \\
I E_{3.3}\left(M_{1}<u_{1}<u_{2}<M_{2} \leq \lambda T\right)=\frac{P I_{b e}}{T}\left[\int_{0}^{M_{1}} t \cdot R_{1}(P, t) d t\right] \\
I E_{3.3}\left(M_{1}<M_{2}<u_{1}<u_{2} \leq \lambda T\right)=\frac{P I_{b e}}{T}\left[\int_{0}^{M_{1}} t \cdot R_{1}(P, t) d t\right] \\
I E_{3.3}\left(M_{1}<M_{2} \leq \lambda T<u_{1}<u_{2}\right)=\frac{P I_{b e}}{T}\left[\int_{0}^{M_{1}} t \cdot R_{1}(P, t) d t\right] \\
I E_{3.3}\left(u_{1}<M_{1}<u_{2}<M_{2} \leq \lambda T\right)=\frac{P I_{b e}}{T}\left[\int_{0}^{u_{1}} t \cdot R_{1}(P, t) d t+\int_{u_{1}}^{M_{1}} t \cdot R_{2}(P, t) d t\right]
\end{gathered}
$$




$$
\begin{gathered}
I E_{3.3}\left(u_{1}<M_{1}<M_{2}<u_{2} \leq \lambda T\right)=\frac{P I_{b e}}{T}\left[\int_{0}^{u_{1}} t \cdot R_{1}(P, t) d t+\int_{u_{1}}^{M_{1}} t \cdot R_{2}(P, t) d t\right] \\
I E_{3.3}\left(u_{1}<M_{1}<M_{2} \leq \lambda T<u_{2}\right)=\frac{P I_{b e}}{T}\left[\int_{0}^{u_{1}} t \cdot R_{1}(P, t) d t+\int_{u_{1}}^{M_{1}} t \cdot R_{2}(P, t) d t\right] \\
I E_{3.3}\left(M_{1}<u_{1}<M_{2}<u_{2} \leq \lambda T\right)=\frac{P I_{b e}}{T}\left[\int_{0}^{M_{1}} t \cdot R_{1}(P, t) d t\right] \\
I E_{3.3}\left(M_{1}<u_{1}<M_{2} \leq \lambda T<u_{2}\right)=\frac{P I_{b e}}{T}\left[\int_{0}^{M_{1}} t \cdot R_{1}(P, t) d t\right] \\
I E_{3.3}\left(M_{1}<M_{2}<u_{1} \leq \lambda T<u_{2}\right)=\frac{P I_{b e}}{T}\left[\int_{0}^{M_{1}} t \cdot R_{1}(P, t) d t\right] .
\end{gathered}
$$

\section{Appendix L: Computation of $I C_{3.3}\left(M_{2} \leq \lambda T\right)$}

$$
\begin{aligned}
& I C_{3.3}\left(u_{1}<u_{2}<M_{1}<M_{2} \leq \lambda T\right)=\frac{C_{b}(1-\beta) I_{b c}}{T} \int_{M_{1}}^{\lambda T} I_{3}(t) d t+\frac{C_{b}(1-\lambda) I_{b c}}{T}\left[\int_{M_{2}}^{\lambda T} I_{3}(t) d t+\int_{\lambda T}^{T} I_{3}(t) d t\right] \\
& I C_{3.3}\left(M_{1}<u_{1}<u_{2}<M_{2} \leq \lambda T\right)=\frac{C_{b}(1-\beta) I_{b c}}{T}\left[\int_{M_{1}}^{u_{1}} I_{1}(t) d t+\int_{u_{1}}^{u_{2}} I_{2}(t) d t+\int_{u_{2}}^{\lambda T} I_{3}(t) d t\right] \\
& +\frac{C_{b}(1-\lambda) I_{b c}}{T}\left[\int_{M_{2}}^{\lambda T} I_{3}(t) d t\right]+\frac{C_{b}(1-\lambda) I_{b c}}{T}\left[\int_{\lambda T}^{T} I_{3}(t) d t\right] \\
& I C_{3.3}\left(M_{1}<M_{2}<u_{1}<u_{2} \leq \lambda T\right)=\frac{C_{b}(1-\beta) I_{b c}}{T}\left[\int_{M_{1}}^{u_{1}} I_{1}(t) d t+\int_{u_{1}}^{u_{2}} I_{2}(t) d t+\int_{u_{2}}^{\lambda T} I_{3}(t) d t\right] \\
& +\frac{C_{b}(1-\lambda) I_{b c}}{T}\left[\int_{M_{2}}^{u_{1}} I_{1}(t) d t+\int_{u_{1}}^{u_{2}} I_{2}(t) d t+\int_{u_{2}}^{\lambda T} I_{3}(t) d t\right] \\
& +\frac{C_{b}(1-\lambda) I_{b c}}{T}\left[\int_{\lambda T}^{T} I_{3}(t) d t\right] \\
& I C_{3.3}\left(M_{1}<M_{2} \leq \lambda T<u_{1}<u_{2}\right)=\frac{C_{b}(1-\beta) I_{b c}}{T}\left[\int_{M_{1}}^{\lambda T} I_{1}(t) d t\right]+\frac{C_{b}(1-\lambda) I_{b c}}{T}\left[\int_{M_{2}}^{\lambda T} I_{1}(t) d t\right] \\
& +\frac{C_{b}(1-\lambda) I_{b c}}{T}\left[\int_{\lambda T}^{u_{1}} I_{1}(t) d t+\int_{u_{1}}^{u_{2}} I_{2}(t) d t+\int_{u_{2}}^{T} I_{3}(t) d t\right]
\end{aligned}
$$




$$
\begin{aligned}
& I C_{3.3}\left(u_{1}<M_{1}<u_{2}<M_{2} \leq \lambda T\right)=\frac{C_{b}(1-\beta) I_{b c}}{T}\left[\int_{M_{1}}^{u_{2}} I_{2}(t) d t+\int_{u_{2}}^{\lambda T} I_{3}(t) d t\right] \\
& +\frac{C_{b}(1-\lambda) I_{b c}}{T}\left[\int_{M_{2}}^{\lambda T} I_{3}(t) d t\right]+\frac{C_{b}(1-\lambda) I_{b c}}{T}\left[\int_{\lambda T}^{T} I_{3}(t) d t\right] \\
& I C_{3.3}\left(u_{1}<M_{1}<M_{2}<u_{2} \leq \lambda T\right)=\frac{C_{b}(1-\beta) I_{b c}}{T}\left[\int_{M_{1}}^{u_{2}} I_{2}(t) d t+\int_{u_{2}}^{\lambda T} I_{3}(t) d t\right] \\
& +\frac{C_{b}(1-\lambda) I_{b c}}{T}\left[\int_{M_{2}}^{u_{2}} I_{2}(t) d t+\int_{u_{2}}^{\lambda T} I_{3}(t) d t\right] \\
& +\frac{C_{b}(1-\lambda) I_{b c}}{T}\left[\int_{\lambda T}^{T} I_{3}(t) d t\right] \\
& I C_{3.3}\left(u_{1}<M_{1}<M_{2} \leq \lambda T<u_{2}\right)=\frac{C_{b}(1-\beta) I_{b c}}{T}\left[\int_{M_{1}}^{\lambda T} I_{2}(t) d t\right]+\frac{C_{b}(1-\lambda) I_{b c}}{T}\left[\int_{M_{2}}^{\lambda T} I_{2}(t) d t\right] \\
& +\frac{C_{b}(1-\lambda) I_{b c}}{T}\left[\int_{\lambda T}^{u_{2}} I_{2}(t) d t+\int_{u_{2}}^{T} I_{3}(t) d t\right] \\
& I C_{3.3}\left(M_{1}<u_{1}<M_{2}<u_{2} \leq \lambda T\right)=\frac{C_{b}(1-\beta) I_{b c}}{T}\left[\int_{M_{1}}^{u_{1}} I_{1}(t) d t+\int_{u_{1}}^{u_{2}} I_{2}(t) d t+\int_{u_{2}}^{\lambda T} I_{3}(t) d t\right] \\
& +\frac{C_{b}(1-\lambda) I_{b c}}{T}\left[\int_{M_{2}}^{u_{2}} I_{2}(t) d t+\int_{u_{2}}^{\lambda T} I_{3}(t) d t\right] \\
& +\frac{C_{b}(1-\lambda) I_{b c}}{T}\left[\int_{\lambda T}^{T} I_{3}(t) d t\right] \\
& I C_{3.3}\left(M_{1}<u_{1}<M_{2} \leq \lambda T<u_{2}\right)=\frac{C_{b}(1-\beta) I_{b c}}{T}\left[\int_{M_{1}}^{u_{1}} I_{1}(t) d t+\int_{u_{1}}^{\lambda T} I_{2}(t) d t\right] \\
& +\frac{C_{b}(1-\lambda) I_{b c}}{T}\left[\int_{M_{2}}^{\lambda T} I_{2}(t) d t\right] \\
& +\frac{C_{b}(1-\lambda) I_{b c}}{T}\left[\int_{\lambda T}^{u_{2}} I_{2}(t) d t+\int_{u_{2}}^{T} I_{3}(t) d t\right]
\end{aligned}
$$




$$
\begin{aligned}
I C_{3.3}\left(M_{1}<M_{2}<u_{1} \leq \lambda T<u_{2}\right)= & \frac{C_{b}(1-\beta) I_{b c}}{T}\left[\int_{M_{1}}^{u_{1}} I_{1}(t) d t+\int_{u_{1}}^{\lambda T} I_{2}(t) d t\right] \\
& +\frac{C_{b}(1-\lambda) I_{b c}}{T}\left[\int_{M_{2}}^{u_{1}} I_{1}(t) d t+\int_{u_{1}}^{\lambda T} I_{2}(t) d t\right] \\
& +\frac{C_{b}(1-\lambda) I_{b c}}{T}\left[\int_{\lambda T}^{u_{2}} I_{2}(t) d t+\int_{u_{2}}^{T} I_{3}(t) d t\right]
\end{aligned}
$$

\section{REFERENCES}

[1] Cheng, M., Zhang, B. and Wang G. (2011).Optimal policy for deteriorating items with trapezoidal type demand and partial backlogging.Applied Mathematical Modelling 35: 3552-3560.

[2] Fabbri, D. and Klapper, L. F.,2011. Trade credit and supply chain, working paper, Cass Business School, City University London.

[3] Goyal, S. K.(1985).Economic order quantity under conditions of permissible delay in payments.Journal of the Operational Research Society 36(4): 335-338.

[4] Goyal, S. K., Chang, C. T. and Teng, J. T. (2008). Inventory lot-size models under trade credits: A review. Asia-Pacific Journal of Operational Research 25(1): 89-112.

[5] Ho, C. H., 2011. The optimal integrated inventory policy with price - and - credit linked demand under two - level trade credit. Computers \& Industrial Engineering, 60(1), 117-126.

[6] Huang, Y. F., 2003. Optimal retailer's ordering policies in the EOQ model under trade credit financing. Journal of the Operational Research Society, 54,1011-1015.

[7] Klapper, Laeven, L. L. and Rajan, R., 2012. Trade credit contracts. The Review of Financial Studies, 25, 838-867.

[8] Min, J., Zhou, Y. W. and Zhao, J., 2010.An inventory model for deteriorating items under stock-dependent demand and two-level trade credit. Applied Mathematical Modelling, 34(11), 3273-3285.
[9] Ouyang, L. Y., Teng, J. T., Goyal, S. K. And Yang, C. T. (2009). An economic order quantity model for deteriorating items with partially permissible delay in payments linked to order quantity. European Journal of Operational Research 194(2): 418-431.

[10] Shah, N. H.,Soni, H. N. and Jaggi, C. K. (2010). Inventory model and trade credit: Review. Control and Cybernetics 39(3): 867-884.

[11] Shah, N. H. and Raykundaliya, N., 2011. Co-ordinated inventory models with two-level credit policy and a price negotiation scheme in declining market. International Journal of Data Analysis Techniques and Strategies, 3(2), 202-219.

[12] Teng, J. T. and Chang, C. T., 2009. Optimal manufacturer's replenishment policies in the EPQ model under two-levels of trade credit policy. European Journal of Operational Research, 195, 358-363.

[13] Teng, J. T., Min, J. and Pan, Q. H., 2012.Economic order quantity model with trade credit financing for non-decreasing demand. Omega, 40(3), 328-355.

[14] Zhou, J., 2009. Impacts of financial collaboration in a three-party supply chain. William E. Simon Graduate School of Business Administration University of Rochester, New York, Working paper.

[15] Zhou, Y. W., Zhong, Y. G. and Wahab, M. I. M., (2012).How to make the replenishment and payment strategy under flexible two-part trade credit.Accepted: Computers and Operations

Research,http://dx.doi.org/10.1016/j.cor.2012.12.013. 